CARTAS AL EDITOR

\section{Seccional residentes cirugía general Sociedad de Cirujanos de Chile}

\section{Señor Editor:}

En la Jornada de Residentes del "LXXXVI Congreso Chileno e Internacional de Cirugía" de la Sociedad de Cirujanos de Chile se conformó por primera vez la Seccional de Residentes de Cirugía General de la Sociedad de Cirujanos de Chile. Con el objetivo de obtener una mesa representativa fue conformada en un inicio por 5 integrantes, 1 Residente de una Universidad del norte del país, 2 Residentes de Universidades de la Región Metropolitana y 2 Residentes de Universidades del sur de Chile. A través de un sistema de votación a mano alzada entre los asistentes a la Jornada de Residentes quedó integrada por:

- Dra. Francisca Correa. Universidad de Chile.

- Dr. Leonardo Parada. Pontificia Universidad Católica de Chile.

- Dr. Leonardo Cárcamo. Universidad Austral de Chile.

- Dr. Rodrigo Reyes. Universidad de Concepción.

- Dr. Francisco Rodríguez. Universidad Católica del Norte Sede Coquimbo.

La creación de la Seccional de Residentes de Cirugía General da réplica a una de las propuestas del plan de trabajo del actual Directorio de la Sociedad de Cirujanos de Chile, encabezado por el Dr. Mario Uribe y el Dr. Eduardo Coddou, quienes desde un comienzo han manifestado su intención en fortalecer el vínculo de la Sociedad de Cirujanos con los Residentes de programas de formación, de modo de permitir una incorporación más expedita y crear un temprano sentido de pertenencia de los Residentes hacia la Sociedad de Cirujanos de Chile. Por otro lado, la conformación de esta Seccional da respuesta a un sentir generalizado entre los Residentes de Cirugía General de Chile, que es la creación de un estamento representativo en el cual poder canalizar las múltiples inquietudes y propuestas, no sólo en el ámbito académico y científico-quirúrgico, sino además con un profundo componente gremial, que permita representar de manera objetiva y veraz la realidad de los programas de formación en Cirugía General en Chile ${ }^{1}$.

En la actualidad existen 13 universidades que imparten el programa de especialización en Cirugía General en Chile, las realidades que engloban a cada uno de estos programas son disímiles, algunas universidades cuentan con varias sedes, otras imparten programas no acreditados ${ }^{2}$, o son nuevas sin egresados y/o en proceso de acreditación, así como realizan su formación en centros del sistema público, centros del sistema privado y/o FFAA, y algunos centros deben realizar parte de su formación en universidades de otras regiones. Los programas de formación no son iguales ${ }^{3}$, presentan importantes diferencias en relación a rotaciones obligatorias, contenidos mínimos y número de cirugías exigidas, entre otros ítems que activan el sentido de alarma sobre la real homogeneidad de los egresados de programas de formación en Cirugía General en nuestro país ${ }^{3}$.

Las diferencias que viven los Residentes de Cirugía General en Chile sobrepasan el ámbito académico de la formación médico-quirúrgica, se debe considerar además los distintos sistemas de ingreso a estos programas, entre ellos: MGZ, APS, FORDIR, CONES, FOREBAS, FFAA, Autofinanciado, Servicio de Salud, etc. Lo anterior sin lugar a dudas constituye un factor determinante al momento de evaluar las condiciones actuales de los Residentes, en particular para aquellos que bajo el régimen de autofinanciamiento deben compatibilizar sus deberes como Residentes con otras actividades. La creación reciente de concursos de especialidades médicas bajo el compromiso de retorno por el doble del período formativo a Servicios de Salud críticos en nuestro país abre una interrogante sobre las condiciones en las cuales los egresados podrán desarrollar su práctica quirúrgica en zonas extremas, así como las posibilidades reales de realizar un programa formal de sub-especialización y/o mantener una formación de postgrado continua.

Nuestro objetivo inicial será realizar el "Catastro Nacional de Residentes de Cirugía General”, para lo cual necesitaremos trabajar en conjunto con el Directorio de la Sociedad de Cirujanos de Chile y los Directores de Postgrado de todas las Universidades que imparten programas de formación en Cirugía General; una vez obtenida dicha información comenzaremos la etapa de evaluación y diagnóstico, para exponer de manera representativa al Directorio nuestro plan de trabajo, que deberá finalizar en la Jornada de Residentes de Cirugía General organizada por la Seccional de Residentes durante el próximo "LXXXVII Congreso Chileno e Internacional de Cirugía" en la ciudad de Antofagasta eligiendo al nuevo Directorio de la Seccional y aprobando nuestros primeros estatutos. En razón de lo anterior hacemos un llamado enérgico a todos los Residentes de Cirugía General de Chile a enviar sus datos de contacto a residentescirugiachile@gmail.com, a mantener una participación activa y propositiva, y 
de esta forma comenzar a construir los pilares de esta organización que buscará constituir un referente en el ámbito académico-científico durante nuestra etapa de formación, así como un representante y catalizador de las principales inquietudes y propuestas de todos sus miembros.

\section{Dr. Francisco Rodríguez Vega} Residente Cirugía General Universidad Católica del Norte Sede Coquimbo Seccional de Residentes Cirugía General Sociedad de Cirujanos de Chile residentescirugiachile@gmail.com

\section{Referencias}

1. Espinoza R, Danilla S, Valdés F, San Francisco I, Llanos O. Evaluación de los Programas de Formación en Cirugía General. Encuesta a los alumnos de postítulo. Rev Med Chile 2009;137: 940-5.

2. López J. Certificación y Recertificación de Especialistas en Cirugía General. Una mirada desde CONACEM. Rev Chil Cir. 2013;65:560-6.

3. Hepp J, Csendes A, Ibáñez F, Llanos O, San Martín S. Programa de la especialidad Cirugía General. Definiciones y propuestas de la Sociedad de Cirujanos de Chile. Rev Chil Cir. 2008;60(1):. 